\title{
FUKÚ Y EL LEGADO \\ POSCOLONIAL DE \\ OCCIDENTE EN \\ LA MARAVILLOSA \\ VIDA BREVE DE \\ ÓSCAR WAO*
}

José Espericueta**

Más de la primera mitad de la novela de Junot Díaz La maravillosa vida breve de Óscar Wao, el narrador relata el "comienzo" de la historia o el inicio de las tragedias y la violencia que afectaron a la familia Cabral de León durante más de tres generaciones. La historia familiar inicia con una maldición: el fukú americanus. Esta maldición se caracteriza por episodios de extrema violencia y una incapacidad para realizar una conexión emocional o amorosa con otros. El temerario e irreverente narrador de Junot Díaz, Yunior, ahonda en este inicio en su esfuerzo por entender los males de la familia, pero también la más amplia historia de violencia y represión en la República Dominicana. Esta historia comienza, según cabe suponer, con el patriarca de la familia, Abelardo, y su detención por el dictador dominicano Rafael Leónidas Trujillo. Sin embargo, Yunior proporciona una narrativa paralela en notas al pie que interrumpen la historia familiar. Estas notas universalizan el relato familiar y lo transforman en una experiencia colectiva de colonialismo y explotación que data de 1492. Según Yunior, normalmente no hablan de la historia de los males familiares y los orígenes de su fukú: "cuando la familia habla de ellos - que es casi nunca- siempre empiezan en el mismo lugar: con Abelardo y las cosas malas que dijo sobre Trujillo ${ }^{22}$. ${ }^{1}$ Pero en la

* Traducción de Carlos Gutiérrez Lozano.

** Modern Languages and Literatures, Universidad de Dallas.

${ }^{1}$ Junot Díaz, The brief wondrous life of Oscar Wao, 2007, Nueva York, Penguin, p. 211. 
nota 22, Yunior cuestiona este "inicio" y propone otro que retrase quinientos años los orígenes de la desgracia:

Desde luego que hay otros inicios ciertamente mejores. Si me preguntan, habría empezado cuando los españoles "descubrieron" el nuevo mundo o cuando Estados Unidos invadió Santo Domingo en 1916, pero si ese fue el comienzo que los De León escogieron para ellos, ¿quién soy yo para cuestionar su historiografía? [p. 211].

Así, la nota cuestiona la historia familiar. Además, la reconstrucción de Yunior de los sucesos de la novela está ligada a su propia incertidumbre. Como dice Mónica Hanna, "al recalcar la naturaleza artificial de todas las historias, la narrativa obliga al lector a examinar las estructuras de poder detrás del acto de narrar". ${ }^{2}$ Yunior finge que acepta ese inicio que no prefiere, pero establece una tenue coexistencia de las dos narrativas: la primera, comienza cuando un joven doctor llamado Abelardo se niega a entregar a su bella hija al dictador del país. Abelardo es arrestado y torturado, y pasa el resto de sus días mentalmente incapacitado en una de las peores cárceles del país. La segunda es una plaga traída al país por la expansión occidental:

Decían que había venido de África, en los gritos de los esclavos; que era la maldición mortal de los taínos, lanzada cuando un mundo pereció y comenzó otro; que era un demonio traído al mundo por una puerta de pesadilla que se abrió en las Antillas. Fukú americanus, o más coloquialmente, fukú: una maldición o una condenación, y específicamente, la maldición y la condenación del Nuevo Mundo. Se llama también fukú del Almirante, porque el Almirante fue su partera y una de sus grandes víctimas europeas. Aunque "descubrió" el Nuevo Mundo, el Almirante murió miserable y sifilítico, escuchando (dizque) voces divinas. En Santo Domingo, la tierra que más amó [...] el nombre mismo del Almirante ha llegado a ser sinónimo de ambas clases de fukú, la pequeña y la grande. Decir su nombre en voz alta o incluso oírlo es atraer la calamidad sobre la cabeza de uno y de sus seres queridos. [p. 1].

${ }^{2}$ Monica Hanna, “'Reassembling the fragments': Battling historiographies, Caribbean discourse, and nerd genres in Junot Díaz's The brief wondrous life of Oscar Wao", Callaloo, 33.2, primavera de 2010, pp. 498-520. 
Fukú tiene múltiples significados, desde "mal de ojo" hasta algo mucho más grande. Pero en la cita anterior toma dimensiones universales y se entiende como una tendencia básica en los acontecimientos históricos, en la expansión occidental y la esclavitud, la acumulación de poder y la opresión de los pueblos. La narrativa, y por extensión la novela misma, es en parte tragedia familiar y en parte historia poscolonial que arremete contra un pasado de violencia y explotación.

De hecho, es una historia universal, la historia de los individuos atrapados por fuerzas violentas inmanejables que cambian el curso de las narrativas personales, nacionales e internacionales.

En este artículo se examinan las tragedias provocadas por el fukú en las experiencias poscoloniales latinoamericanas y latinoestadounidenses. De particular interés es la relación entre las narrativas familiar y nacional y la comprensión del fukú como un legado poscolonial que persiste en la historia de la República Dominicana pero también, en último término, como un tipo de la universal condición humana. ${ }^{3}$ En última instancia, propongo que mientras la novela se rebela contra la opresión que ha constituido gran parte de la historia de la isla, rearticula también poderosamente la experiencia (poscolonial, inmigrante) individual dentro de la más amplia experiencia estadounidense.

Para continuar con los temas de esta semana de discusión sobre las tradiciones occidentales, las humanidades y su papel esencial en la educación de nuestros estudiantes, propongo una línea de investigación interrelacionada pero separada: ¿Cómo entendemos las modernas identidades inmigrantes en el marco de los modos tradicionales de representación? ¿Cuál de sus historias? La hibridez literaria de Óscar Wao proporciona un camino necesario de aproximación a la experiencia dominicana. Sin embargo, la novela igualmente sirve como un correctivo a la narrativa histórica "oficial", sea simplemente por su valor educativo o sea como una historia de las voces silenciadas por el régimen

${ }^{3}$ Respecto al problemático prefijo "post" de la experiencia poscolonial véase J. Jorge Klor de Alva, "The postcolonization of the (Latin) American experience: A reconsideration of 'colonialism', 'postcolonialism', and 'mestizaje', en Gyan Prakash (comp.), After colonialism: Imperial histories and postcolonial displacements, 1995, Princeton, Princeton University Press, pp. 241-75. 
de Trujillo. El narrador Yunior llama a su texto una "zafa", o contrahechizo, que está destinado a interceder en la continua violencia de un régimen brutal y su dominación sobre la realidad cotidiana. Para este fin, el texto cumple la finalidad de ampliar los parámetros con los que examinamos las modernas historias y experiencias occidentales.

La novela se centra en la familia de Óscar de León, un escritor y ghetto nerd de la primera generación de dominicanos estadounidenses que tiene dificultades para encontrar el amor e incluso la atención de una mujer. El término ghetto nerd parecería una contradicción, pero para el narrador Yunior la principal ironía es que Óscar es un dominicano que no tiene varias novias. Se deba a su obesidad o a su afición a los juegos y la ciencia ficción, Óscar es un marginado tanto de su comunidad dominicana como de la estadounidense. Pero incluso cuando Yunior cuestiona la dominicaneidad de Óscar, al mismo tiempo admite que la afición por la ciencia ficción parece convenir a un inmigrante dominicano:

Puede haber sido una consecuencia de ser antillano (¿quienes son más de ciencia ficción que nosotros?) o de vivir en la República Dominicana los primeros dos años de su vida y luego mudarse abrupta y desgarradoramente a Nueva Jersey. Una simple tarjeta verde cambia no solo de mundos (del tercero al primero), sino también de siglo. [p. 22].

Las proporciones sobrenaturales de la alienación de Óscar subrayan las dificultades que encara entre dos culturas (mundos). Yunior abunda sobre la condición de Óscar en un momento de simpatía: "¿Quieres saber lo que se siente ser un hombre X? Basta que seas chico listo y negro en un gueto estadounidense. Mamma mia! Es como tener alas de murciélago o un par de tentáculos en el pecho" (p. 22). La misma alienación sigue a Óscar desde la secundaria hasta la universidad, desde la República Dominicana hasta Nueva Jersey y de vuelta a la República Dominicana, en medio de obsesiones vergonzosas con mujeres, un intento de suicidio y una aventura en la República Dominicana en busca de sus orígenes. Este último viaje reúne la historia personal de su familia con el legado persistente de la dictadura de Trujillo. 
Al final, se vuelve clara la conexión entre la alineación de Óscar y la soledad y décadas de violencia histórica. Los intentos de Óscar por realizarse por medio del amor se topan con la violencia extrema, por un aparato represivo que está empeñado por conservar su poder reprimiendo a quienes lo impugnen.

Yunior amplía su historia de tragedia y soledad para incluir a la hermana de Óscar, Lola (que es su novia ocasional) y Belicia, la mamá de Óscar y Lola. La narración de la vida de Belicia en la República Dominicana (antes de mudarse a Nueva Jersey) es una historia paralela de la violencia y la represión en la era de Trujillo. Sus inicios, incluso su vida entera en la República Dominicana, son inseparables tanto de Trujillo como del fukú. De niña fue vendida y llevada de casa en casa trabajando como sirvienta. Esto ocurrió después de que su padre Abelardo fuera encarcelado por Trujillo y el resto de su familia cercana muriera en condiciones trágicas. Sin embargo, es el deseo de amar y su imposibilidad lo que más le duele a Beli. Su amorío adolescente con un tipo conocido como el Gánster (uno de los hombres de confianza del dictador) es su más directa relación con Trujillo. El amorío representa una nueva vida para Beli, en la que es admirada y mimada (muy lejos de sus pobres comienzos). Pero el Gánster está casado con la hermana de Trujillo, un hecho que sella el destino de Beli. En un acto que vincula el fin trágico de Beli con la represión de Trujillo del pueblo dominicano, es golpeada brutalmente y abandonada medio muerta por los hombres del dictador. Eso la obliga a huir a Estados Unidos, donde inicia una nueva vida.

Aunque es indiscutible que Beli tiene un papel en la sucesión de acontecimientos que casi la llevan a la muerte (porque se niega a aceptar el matrimonio de el Gánster), los hechos sobrenaturales que rodean su golpiza apuntan al poder del fukú sobre su vida y, por extensión, a la violencia generalizada en la República Dominicana. Su golpiza es precedida por la premonición de un hombre sin rostro, una aparición que se presenta muchas veces en la novela como presentimiento de la violencia (siempre directa o indirectamente relacionada con Trujillo). A pesar de que el capítulo de la golpiza se titula "Elección y consecuencias", en alusión a las decisiones de Beli, el componente espiritual de su 
salvación y la derrota temporal del fukú se vuelven protagónicos. La situación adquiere un carácter aún más sobrenatural (y espiritual) cuando Beli tiene visiones de su madre adoptiva, la Inca, cuando reza con los vecinos de su casa. Su salvación definitiva viene de una mangosta parlante que la rescata del campo y la lleva a un camino donde la encuentra un grupo de músicos. La golpiza que precipita el escape de Beli a Nueva Jersey es uno de los muchos inicios de la novela en un sentido práctico y metafórico. Aunque desemboca en su corto matrimonio y en el nacimiento de Lola y Óscar, el trauma físico y emocional se vincula simbólicamente con la soledad y la imposibilidad de amar que aqueja a los personajes de la novela.

Así pues, mientras que la tragedia de cada personaje es inherentemente personal, todas obedecen a fuerzas que están lejos de su control, con lo que se insertan en una narración más universal de la violencia. Lola, la hermana de Óscar, está parcialmente libre de la maldición de la familia, aun cuando su marca es clara. Por rebelarse contra su mamá, Lola es enviada a la República Dominicana a vivir con la Inca. Al principio le va bien y es feliz (es una velocista estrella en la secundaria local, tiene un novio dominicano que la adora), pero con la felicidad llegan la confusión y los presagios que se originan en la desgracia de la familia y en la violencia que aqueja a la República Dominicana. Para Lola, el viaje a la República Dominicana es el regreso a los orígenes de la familia. Allí, con la Inca, Lola conoce el pasado de la familia y su insoportable poder sobre su propio presente. Antes incluso de conocer la historia, Lola siente el peso de la maldición de la familia en la República Dominicana. Cuando la Inca se prepara a contarle la historia, Lola observa: "Estaba esperando lo que iba a decirme. Estaba esperando a que comenzara" (p. 75, las cursivas son mías). La fuerza de su pasado golpea a Lola “como un huracán” (p. 75), pero también se entiende como un principio. El retorno de Lola a sus orígenes en la República Dominicana da lugar a una nueva comprensión de la historia de violencia que está en la base de su experiencia familiar.

La apariencia física de Óscar, su carácter de nerd y su incapacidad para tratar con las mujeres no parece ser un síntoma de fukú, sino más bien un tipo de alienación que pone de relieve su experiencia como inmi- 
grante que está entre dos mundos sin pertenecer a ninguno. Al principio, poco de su historia parece sobrenatural, excepto por los cómics y novelas de ciencia ficción que lee. Pero cuando Óscar madura y pasa de la preparatoria a la universidad, los intentos fallidos por ganar el afecto de las mujeres y lo inevitable de su soledad lo llevan a la República Dominicana en busca de sus propios orígenes. El viaje le trae una de sus obsesiones más intensas: una prostituta casi semirretirada llamada Ybón. Esto marca también su completa integración a la historia de la familia. La experiencia dominicana, tanto la inmersión en el pasado como los intentos frenéticos de lograr una conexión romántica, refuerzan los vínculos entre las narrativas personales y nacional de la novela. Al reescribir la historia de su mamá, Óscar se enamora de Ybón, que es la novia de un capitán de la policía militar. El noviazgo de Ybón, la tolerancia de Óscar y el aparente afecto son suficientes para afianzar la obsesión de Óscar y para incitar la ira del capitán. El novio golpea a Óscar (y aparece el hombre sin rostro). Óscar vuelve a Estados Unidos para conseguir dinero prestado. Regresa a Dominicana en busca de Ybón y, a fin de cuentas, para encontrar su propia muerte. Sin embargo, renunciando a su habitual resistencia a las supersticiones dominicanas, Óscar le dice a Yunior en una de sus últimas conversaciones que lo ocurrido está fuera de su control; es fukú.

Lo que escribe Óscar durante su estancia en la República Dominicana se convierte en una investigación sobre el fukú y su propia soledad personal. En una carta a Lola antes de su muerte, habla de sus "descubrimientos", le cuenta lo que aprendió de sus orígenes y, por extensión, de los orígenes del fukú. Sin embargo, el narrador no logra recuperar los últimos manuscritos de Óscar, lo cual frustra cualquier epifanía final en la novela. Según Óscar, su último envío (que nunca llega) "contiene todo lo que he escrito sobre este viaje. Todo lo que pienso que necesitarás. Entenderás cuando leas mis conclusiones (es la cura para lo que nos aflige [...] El ADN cósmico)" (p. 333). La "cura" a la que Óscar alude queda deliberadamente en la oscuridad. Mientras tanto, el libro desaparecido alude al tratado de su abuelo sobre la posible relación de Trujillo con las artes oscuras y a las historias suprimidas 
en el régimen trujillista. La rebelión personal de Óscar contra los partidarios de Trujillo (él sería un vengador que los esperaría en otro mundo) antes de su muerte y la concreción física de su relación con Ybón dejan entrever un giro en su fortuna. Al consumar su relación con Ybón, Óscar experimenta una intimidad real con otra persona. Menos que el acto sexual —escribe-, son las "pequeñas intimidades" inesperadas que nunca había experimentado lo que más lo impresionó (como las conversaciones íntimas o conocer los hábitos de Ybón). “¡Así que esto es de lo que todos hablan! ¡Diablos! Si lo hubiera sabido ¡La belleza! ¡La belleza!” (p. 335).

Pero el fukú aparece inevitablemente, lo que no sorprende considerando la dimensión universal que le confirió Junot Díaz. Las palabras con las que termina la novela (“¡La belleza! ¡La belleza!”) podrían contrarrestar mucho de la soledad y la mala fortuna de los protagonistas. Pero este momento mágico es impotente para derrotar al fukú que lleva a la muerte de Óscar a manos de la policía militar y que sugiere la continuación del sistema opresor después de Trujillo. Mientras tanto, la pérdida de los manuscritos de Óscar ("la cura para lo que nos aflige") complica la intención de Yunior de escribir una historia para neutralizar el fukú que aqueja a tantos. La revolución radical se frustra y el fukú y el legado de violencia y opresión salen ilesos. Además, la ubicación del fukú en el ámbito internacional dificulta su derrota. Yunior hace clara la conexión entre el fukú y las historias dominicanas/estadounidenses en los irónicos comentarios de las notas al calce, en las digresiones sobre los secuaces de Trujillo y sus amoríos con jóvenes actrices estadounidenses (Ramfis y Kim Novak) o en notas más serias sobre la participación militar estadounidense después de la dictadura de Trujillo.

Pero el momento del arresto del abuelo Abelardo y el bombardeo estadounidense de Hiroshima y Nagasaki funden ominosamente la tragedia y la destrucción en el espacio de un solo párrafo. Después de reconstruir lo que habría sido el último momento de felicidad de Abelardo, Yunior escribe:

Quisiera quedarme en este momento, quisiera alargar los últimos días felices de Abelardo, pero es imposible. La semana siguiente, dos ojos 
atómicos se abrieron sobre centros civiles en Japón y, aunque nadie lo sabía aún, rehicieron al mundo. Ni dos días después de que las bombas atómicas dejaran su marca permanente en Japón, Socorro [la esposa de Abelardo] soñó que el hombre sin rostro se inclinaba sobre la cama de su esposo y ella no podía gritar, no podía decir nada, y a la siguiente noche lo soñó sobre sus hijos. He tenido sueños — le dijo a su marido-, pero él hizo un gesto de desprecio con las manos. Socorro empezó a vigilar la entrada de su casa y prendió veladoras en su cuarto. En Santiago, Abelardo besa las manos de Lidia [su amante] y ella suspira de placer y nos encaminamos a la victoria en el Pacifico y tres oficiales de la policía secreta llegan en su brillante Chevrolet a casa de Abelardo. Ya es la caída. [p. 236-7, las cursivas son mías]

La "caída" tiene una resonancia particularmente profunda. No solo es otro comienzo de los males para la familia Cabral, que pone en movimiento una espiral de violencia y muerte, sino que se conecta con la destrucción a gran escala de las bombas atómicas que "rehacen el mundo". Como historia sobre inmigrantes y, en cierto grado, sobre la experiencia estadounidense, la novela de Díaz trasciende la experiencia dominicana poscolonial y explora los vínculos entre la historia y la política. En última instancia, la violencia no tiene límites y la tragedia adquiere proporciones universales.

Es necesario regresar a la rebelión de Óscar contra sus captores y el giro de su fortuna (al menos en el amor) para examinar el tratamiento en la novela de la acción personal. A pesar de ser uno de los personajes con más defectos y el único para quien el amor es más elusivo, Óscar rompe el ciclo de la soledad y realiza una conexión íntima que lo distingue de otros personajes de la novela. Así se opera un cambio significativo en la novela, que además dialoga con el bien conocido tema de Cien años de soledad de Gabriel García Márquez, en el que generaciones de protagonistas sufren la soledad y carecen de vínculos íntimos. Si hay redención en la novela (o, a fin de cuentas, para la humanidad) no radica meramente en la necesidad de contar las historias de los oprimidos de la sociedad, sino en la búsqueda de mejorar, de realizarse y de amar. Las palabras finales de Óscar: “¡La belleza! ¡La belleza!”, son 
una especie de correctivo de El corazón de las tinieblas de Joseph Conrad (una novela sobre el colonialismo y la explotación), en la cual la famosa frase de Kurtz (“¡El horror! ¡El horror!”) reflejaría la propensión de la humanidad a la barbarie en el contexto colonial. La maravillosa vida breve de Óscar Wao se rebela contra el colonialismo y el imperialismo occidental incluso cuando mira al interior, al potencial del individuo lo mismo para la violencia que para para el mejoramiento personal y la autorrealización.

Las palabras de dolor de Lola ante la muerte de Óscar son una denuncia de la propensión de la humanidad por la violencia y del ciclo inquebrantable de opresión. Pero mientras que la frase "diez millones de Trujillos es todo lo que somos" (p. 324) podría ser la expresión de una condición que se generó como secuela de la violencia y la corrupción después de la dictadura, se interioriza con el mismo vigor en la propia acción del individuo. En este sentido, la novela es liberadora y optimista incluso cuando dirige severas críticas a los regímenes imperialistas y dictatoriales. El fukú es ubicuo, pero también lo es la zafa, su contrahechizo por medio de la fuerza liberadora de escribir y de la vinculación humana.

Lo que queda, entonces, es el lugar de esta novela en la literatura, la tradición y la historia de Occidente. Como profesor de literatura, me interesan las tradiciones literarias, específicamente las tradiciones hispánica y latinoamericana. Como hemos visto, el texto cumple un papel histórico importante de complementar la historia occidental y de sacudir al lector (en particular, al lector estadounidense) para que enfrente una historia que puede darse el lujo de ignorar. Yunior rechaza esta posibilidad en su primera nota:

Para los que se perdieron sus dos segundos obligatorios de historia dominicana: Trujillo, uno de los dictadores más infames del siglo XX, gobernó la República Dominicana entre 1930 y 1961 con una brutalidad implacable y despiadada. [p. 2]

En este plano, el lector queda invitado a examinar su propia ignorancia de una historia que es manifiestamente occidental. La interconexión 
de la historia estadounidense y dominicana es un tema del que ya he hablado; sin embargo, vale la pena recordar la función de las notas que completan la narración de la novela con la historia real. Colocar las notas al calce del texto pone de relieve la continua presencia de una historia violenta en la vida cotidiana de los protagonistas. Al mismo tiempo, fortalece la capacidad del texto de ampliar nuestra comprensión de las historias latinoamericana y estadounidense y de las experiencias migratorias.

La novela abunda sobre las concepciones de identidades y experiencias de inmigrantes, al tiempo que su género híbrido afirma una diversidad peculiar en las tradiciones y cánones literarios de Estados Unidos. Como señala William Deresiewicz, pocos lectores no se sentirían rechazados por las numerosas referencias de la novela, si no simpatizaran con la experiencia de "la pesadilla de las juntas a las ocho de la mañana de la Asociación de Lenguas Modernas", una familiaridad con la pintura de John Singer Sargent, el íntimo conocimiento de la historia dominicana o las innumerables referencias a los géneros especulativos. ${ }^{4}$ Esto último, quizá más que cualquier otra referencia literaria, explica mejor la realidad dominicana contemporánea y da a los lectores qué pensar cuando consideran términos como "primer y tercer mundos". Desde la primera nota sobre Trujillo, aprendemos de sus poderes sobrenaturales:

A primera vista, no era más que el típico caudillo latinoamericano, pero su poder era extremo de una manera que pocos historiadores o escritores han sabido captar o siquiera imaginar. Era nuestro Sauron, nuestro Arawn, nuestro Darseid, nuestro único y futuro dictador, un personaje tan descabellado, tan perverso, tan terrible que ni siquiera un escritor de ciencia ficción lo superaría. Era conocido por cambiar TODOS LOS NOMBRES de TODOS LOS MONUMENTOS de la República Dominicana para honrarse a él mismo [...] por dirigir el país como si fuera un campo de entrenamiento, por despojar a amigos y aliados de sus puestos y propiedades sin ninguna razón; y por sus habilidades casi sobrenaturales. [p. 3]

${ }^{4}$ William Deresiewicz, "Fukú americanus", The Nation, 8 de noviembre 2007, en $<$ http:// www.thenation.com/article/fukuacute-americanus/>. 
Aunque las habilidades sobrenaturales incluían saber cuando alguien hablaba mal de él (una hazaña lograda a través del miedo y una extensa red de policía de inteligencia militar), la "realidad" creada por el (re) nombramiento de monumentos y ciudades es dictatorial y sobrenatural. Esto, junto con las cualidades extraterrestres dadas a los protagonistas inmigrantes y su negrura indican la influencia de géneros especulativos y su importancia para Díaz.

Aunque a veces perturba, esta hibridez literaria no es discordante, sino armoniosa. Algunos lectores se sentirán ajenos al español dominicano, pero los dos idiomas avanzan sin tropezar en la medida que reflejan la posición intermedia o híbrida del inmigrante moderno. A lo largo del texto se intercalan sin traducir palabras en español, integradas poéticamente a las frases: "from the richest jabao in Mao to the poorest güey in el Buey, from the oldest anciano san macorisano to the littlest carajito in San Francisco" (p. 3). Díaz integra voces, lenguajes y dialectos en oraciones rítmicas que parecen correctas y naturales. El buen resultado de esta hibridez es aún más impresionante si se considera la cuestión de la alteridad cultural que está en juego en la novela.

Lo que es particularmente único y refrescante en la novela de Díaz (e instructivo al examinar esta pieza literaria muy contemporánea) es la libertad con la que se acerca a las tradiciones occidentales. El elemento de integración que es común en su obra (géneros, la interconexión de historias, pueblos) se aprecia con más claridad en la aproximación de Díaz a los tropos y tradiciones literarias por excelencia. Sobre las ambigüedades del fukú y su contrahechizo la zafa, Yunior escribe: "antes era más popular, más grande, por decirlo así, en Macondo que en McOndo" (p. 7). Aunque Macondo se asocia (con justa razón) con García Márquez y las generaciones anteriores, Díaz lo acoge aquí. El fukú se presenta como realidad y, potencialmente, superstición. Óscar Wao es a la vez Macondo y McOndo, realismo mágico, ciencia ficción e historia posmoderna todo en uno. Otro tanto ocurre cuando se trata de religión. Cuando la Inca reza por Beli en el momento de su golpiza, Yunior se mete en la narración para anunciar:

Nosotros, plátanos posmodernos, tendemos a desaprobar la devoción católica de nuestras viejas como atávica, un retroceso vergonzoso a tiempos 
antiguos, pero es exactamente en estos momentos cuando toda esperanza se desvanece, cuando el final se acerca, que la oración tiene el dominio. [p. 144]

El "dominio" de la oración no consiste solo en que brote naturalmente en tiempos de crisis, sino que se apodera de la escena con una fuerza sobrenatural, se fusiona con la mangosta y rescata a Belicia de una muerte casi segura.

Díaz no se restringe al abrazar las tradiciones (y herencias) a las que pertenece. Su novela es un ejemplo de un bricoleur inmigrante multicultural y un retrato global de la interconexión (social y política). Su valor contemporáneo radica en su habilidad para obligar al lector a lidiar con la alienación de una realidad particular incluso cuando lo invita a aceptar la naturaleza compartida de esta realidad. Es una impetuosa crítica de la conquista, la dictadura y el imperialismo, incluso cuando exhorta al individuo a ver al interior y enfrentar la responsabilidad de rendir cuentas personales. No ofrece respuestas fáciles a las cuestiones más arduas de la historia de Occidente, pero avanza con optimismo y adopta la conexión y el amor humanos. 
CITAM Derechos Reservados.

La reproducción total o parcial de este artículo se podrá hacer si el ITAM otorga la autorización previamente por escrito. 